\title{
Effect of Insulin and Losartan on Modulation of Insulin-Like Growth Factor 1 Receptor at Heart Level in Diabetic Rats
}

\author{
Anwar B. Bikhazi ${ }^{*}$, a Wael M. Maharsy ${ }^{\text {a }}$, Lina N. Kadi ${ }^{a}$, Nahla G. Issa ${ }^{\text {a }}$, Ghinwa M. Barakat ${ }^{\mathrm{a}}$, \\ Nuha Nuwayri-Salti ${ }^{b}$, George K. Karam ${ }^{\mathrm{a}}$, Omar A. Batal ${ }^{\mathrm{a}}$ and Khalil M. Bitar ${ }^{\mathrm{c}}$ \\ Departments of ${ }^{a}$ Physiology, Human ${ }^{b}$ Morphology and ${ }^{c}$ Physics, American University of Beirut, Beirut, Lebanon
}

\begin{abstract}
This study investigates insulin-like growth factor-1 receptor (IGF-1R) modulation in hearts of streptozotocininduced diabetic rats treated with insulin/angiotensin-II receptor subtype-1 blocker $\left(\mathrm{AR}_{1} \mathrm{~B}\right)$, losartan. Male rats were divided into: normal $(\mathrm{N})$, losartan-treated normal (NL), diabetic (D), insulin-treated diabetic (DI), losartan-treated diabetic (DL), and insulin/losartan co-treated diabetic (DIL) groups. Thirty days post-treatment, rats underwent heart perfusion using $\left[\mathrm{I}^{125}\right]$-labeled IGF-1 to assess receptor-binding affinity on coronary endothelial cells (CE) and cardiomyocytes (CM). This revealed an increase in binding affinity of IGF-1 to its receptor on CE in all groups compared to N. On CM, binding affinity increased in D, DI, and DL compared to N, but was almost normalized in DIL. Western blot analyses and immunohistochemistry done on heart tissues showed decrease in IGF-1R density in DIL versus remaining groups. These results demonstrate a complex interaction between insulin, angiotensin-II, and IGF-1, and mass blockade of myocardial remodeling by $\mathrm{AR}_{1} \mathrm{~B}$ treatment in diabetic state.
\end{abstract}

Keywords: Insulin-dependent-diabetes-mellitus, insulin receptor, insulin-like growth factor 1 receptor, receptor regulation, cardiomyopathy.

\section{INTRODUCTION}

Insulin-like growth factors (IGFs) are insulin related protein hormones believed to be survival factors [1,2], and are of two types: IGF-1 and IGF-2. IGF-1 has one receptor subtype known as the IGF-1 receptor (IGF-1R). The IGF-1Rs are similar to the insulin receptors, and are heterotetrameric proteins with intrinsic tyrosine kinase activity. Moreover, IGF-1 activity is modulated by binding to specific IGF-binding proteins that are not capable of binding to insulin. IGF-1, the IGF-1R, and the binding proteins create an autocrine-paracrine humoral system that is expressed in several tissues. IGF-1, like insulin, activates the extensive phosphorylation of the insulin receptor substrate 1 (IRS-1), a protein with a pivotal role in many of insulin mediated actions [1]. In the heart, the phosphorylation of the IRS-1 leads to the activation of two important pathways, the mitogen activated protein kinase/extra-cellular regulated kinase (MAPK/ERK) pathway that promotes growth and proliferation, and the phosphoinositol-3 kinase (PI-3 K)-Akt pathway which is linked to cellular metabolism and has an anti-apoptotic effect [2,3]. Therefore, several studies have suggested that IGF-1 is involved in myocardial structure and function regulation. In addition to its effects on cell growth and differentiation, IGF-1 was reported to suppress or delay apoptosis of cardiomyocytes (CM) and prolong their survival [3-5]. Certain studies indicated that it can adjust apoptotic signaling cascades in the heart. Therefore, IGF-1 can serve as a potential cardioprotective therapy in many disease states, such as diabetes mellitus and hypertension [4].

*Address correspondence to this author at the Department of Physiology, Faculty of Medicine, American University of Beirut, Beirut, Lebanon; Tel: 961-1-350000, Ext. 4811; Fax: 961-1-744464; E-mail: ab04@aub.edu.lb
Cardiovascular disorders are believed to be the chief causes of morbidity and early death among diabetic patients $[6,7]$. Cardiomyopathy, a specific heart muscle dysfunction that occurs independently of coronary artery disease, may lead to heart failure [7]. Furthermore, our laboratory found that cardiomyopathic alterations in streptozotocin (STZ)induced diabetic rats usually start with apoptosis early after diabetes induction and end with hypertrophy and broad cardiomyopathic damage [8]. Insulin actions are mediated through binding to its tyrosine kinase receptor leading to tyrosine phosphorylation of many proteins, including the IRS-1 and IRS-2 [9]. Recent evidence indicated that Gprotein coupled receptors, like the angiotensin-II receptor subtypes 1 and $2\left(\mathrm{AT}_{1}-\mathrm{R}\right.$ and the $\left.\mathrm{AT}_{2}-\mathrm{R}\right)$, may mimic the effects of receptors acting through tyrosine kinase, such as the insulin receptors, thus resulting in a complex cross talk between the insulin and angiotensin-II (Ang II) signaling pathways $[10,11]$.

Ang II is a potent vasoconstrictor that aids in blood pressure regulation as well as body fluid balance maintenance. In the heart, it acts in both endocrine and paracrine fashions to regulate contractility, impulse propagation, remodeling, growth, and apoptosis [12]. Ang II has two major receptor subtypes, the $\mathrm{AT}_{1}-\mathrm{R}$ and the $\mathrm{AT}_{2}-\mathrm{R}$, where $\mathrm{CM}$ are the major sites for these receptors expression $[14,15]$. The $\mathrm{AT}_{1}-\mathrm{R}$ mediates the classical functions of Ang II in the heart tissue, such as vasoconstriction and blood pressure elevation, mainly through the stimulation of phospholipase $\mathrm{C}$, the mobilization of $\mathrm{Ca}^{2+}$ and the phosphorylation of MAPK [15]. The $\mathrm{AT}_{2}-\mathrm{R}$ seems to act as a sustainable repressor of $\mathrm{AT}_{1}-\mathrm{R}$ signaling pathway $[14,16]$.

Losartan, an angiotensin II selective $\mathrm{AT}_{1}-\mathrm{R}$ blocker $\left(\mathrm{AR}_{1} \mathrm{~B}\right)$ that is used as an antihypertensive drug, was found to counteract Ang II mediated cardiac remodeling besides its role in blood pressure reduction $[17,18]$. Recently, we found 
that in STZ-induced diabetic rats, the co-treatment with insulin and losartan was almost able to totally prevent myocardial remodeling [8]. We also reported that this treatment modality could improve cardiac contraction as well as coronary blood flow in STZ-induced diabetic rats through the modification of the affinity of endothelin-1 (ET-1) to its receptor subtypes $\mathrm{ET}_{\mathrm{A}}-\mathrm{R}$ and $\mathrm{ET}_{\mathrm{B}}-\mathrm{R}$ [19].

This manuscript tackles the effect of treatment with insulin and/or an $\mathrm{AR}_{1} \mathrm{~B}$ on IGF-1R modulation in STZ-diabetic rat hearts.

\section{MATERIALS AND METHODOLOGY}

All experiments were conducted with prior approval of the "Institutional Review Board/Animal House Committee" of the American University of Beirut (AUB-MC). Experimental animals were handled, treated, and sacrificed in accordance with the guidelines of the "American Association for Laboratory Animal Sciences (AALAS)" on "Humane Care and Use of Laboratory Animals".

\section{Animals}

Male Sprague-Dawley rats [200-250g body weight (bw)] purchased from Harland, Netherlands, and bred at the Animal House Unit, American University of Beirut, were set up at four rats per cage (24 animals/group). They were fed $\mathrm{Pu}-$ rina pellets and tap water ad libitum for 30 days, and were kept at constant temperature with 12 hours of light per day until sacrifice.

\section{Study Design and Methods}

\section{Treatment and Monitor Plan}

Rats were divided into six groups as described below, and treated for 30 days:

Group N ( $=24)$ : normal controls receiving a placebo by oral gavage (tap water, $4 \mathrm{~mL} / \mathrm{kg} \mathrm{bw}$ ), once daily $(q d), \mathrm{pH}$ matched with the $\mathrm{pH}$ of the $\mathrm{AR}_{1} \mathrm{~B}$ homogenate.

Group NL $(n=24)$ : normal controls given losartan (Cozaar $^{\mathrm{R}}$, Merck Sharp \& Dohme, Haarlem, Netherlands) by oral gavage at a dosage regimen of $0.7 \mathrm{mg} / \mathrm{kg} \mathrm{bw}, q d$.

Group D $(n=24)$ : STZ-diabetic rats injected intraperitoneally (i.p.) with normal saline solution (NSS) (3 $\mathrm{mL} / \mathrm{kg}$ bw) twice daily (bid) and given placebo (water) orally by gavage $(4 \mathrm{~mL} / \mathrm{kg} \mathrm{bw}, q d)$.

Group DI $(\mathrm{n}=24)$ : STZ-diabetic rats injected i.p. with bovine insulin (0.28 unit/mL, Sigma Chemical Company, St. Louis, MI, USA), 1 unit $/ \mathrm{kg}$ bw, bid, and given placebo water by oral gavage ( $4 \mathrm{~mL} / \mathrm{kg} \mathrm{bw}, q d)$.

Group DL (n=24): STZ-diabetic rats given losartan $(0.7$ $\mathrm{mg} / \mathrm{kg}$ bw, $q d$ ) by oral gavage, and injected i.p. with NSS (3 $\mathrm{mL} / \mathrm{kg}$ bw, bid).

Group DIL (n=24): STZ-diabetic rats were injected i.p. with bovine insulin (1 unit/kg bw), bid, and given losartan by oral gavage $(0.7 \mathrm{mg} / \mathrm{kg} \mathrm{bw}, q d)$.

\section{Induction of Diabetes}

Groups D, DI, DL, and DIL were made diabetic by a single intravenous injection of STZ $(85 \mathrm{mg} / \mathrm{kg} \mathrm{bw}$ ) (Sigma Chemical Company, St. Louis, MI, USA) in saline acidified to $\mathrm{pH} 4.5$ with $0.1 \mathrm{~mol} / \mathrm{L}$ citrate buffer. 72 hours after STZ injection, the rats were checked for diabetes, and blood glucose levels (puncture of tail vein after light nasal sedation with isoflurane) were determined by Accutrend Sensor (Roche Diagnostics GmbH, Mannheim, Germany). Random blood sugar concentration above $250 \mathrm{mg} / \mathrm{dL}$ indicated diabetes.

\section{Body Weight and Blood Sugar}

On a weekly basis, rats were weighed and blood glucose levels were determined using Accutrend Sensor (Roche Diagnostics GmbH, Mannheim, Germany) [8]. Prior to sacrifice the body weights and glucose levels were measured (Table 1).

Table 1. Mean Body Weight And Glucose Level of the Different Groups \pm Standard Error of the Mean (SEM)

\begin{tabular}{|l|c|c|}
\hline \multicolumn{1}{|c|}{ Groups } & $\begin{array}{c}\text { Body Weight } \\
\pm \text { SEM }\end{array}$ & $\begin{array}{c}\text { Glucose Level } \\
\pm \text { SEM }\end{array}$ \\
\hline \hline Normal (N) & $386 \pm 9^{\text {a }}$ & $103 \pm 3^{1}$ \\
\hline Normal + Losartan (NL) & $404 \pm 7^{\mathrm{b}}$ & $97 \pm 3^{2}$ \\
\hline Diabetic (D) & $200 \pm 8^{\mathrm{c}}$ & $524 \pm 22^{3}$ \\
\hline Diabetic + Insulin (DI) & $229 \pm 8^{\mathrm{d}}$ & $540 \pm 16^{4}$ \\
\hline Diabetic + Losartan (DL) & $215 \pm 7^{\mathrm{e}}$ & $555 \pm 19^{5}$ \\
\hline Diabetic + Insulin + Losartan (DIL) & $208 \pm 8^{\mathrm{f}}$ & $541 \pm 20^{6}$ \\
\hline
\end{tabular}

For body weight, (a, b), (a, c), (a, d), (a, e), (a, f), (b, c), (b, d), (b, e), (b, f), (c, d) are significant. All the rest are not significant. For glucose level, $(1,3),(1,4),(1,5),(1,6)$, $(2,3),(2,4),(2,5),(2,6)$ are significant. All the rest are not significant.

\section{Procedures}

\section{Heart Perfusion}

Each of the groups was divided into two subgroups: the first subgroup $(n=8)$ was perfused with Ringer Lock buffer only [Ringer Lock buffer contains 9.0 grams of $\mathrm{NaCl}, 0.43 \mathrm{~g}$. of $\mathrm{KCl}, 0.24 \mathrm{~g}$ of $\mathrm{CaCl}_{2}, 0.10 \mathrm{~g}$ of $\mathrm{NaHCO}_{3}$, and $1 \mathrm{~g}$ of Dglucose. Distilled water (DW) was added up to a total volume of 1 liter. The buffer was then oxygenated for 15 minutes with $95 \%$ oxygen and $5 \%$ carbon dioxide in a water bath at $37^{\circ} \mathrm{C}$; ; the second $(n=8)$ was perfused with 20 $\mathrm{mmol} / \mathrm{L}$ of 3-[(3-cholamidopropyl)dimethylammonio]-1propanesulfonate (CHAPS; Sigma Chemical Company, St. Louis, MO) to remove the endothelial lining. Prior to sacrifice, rats were weighed, and then anesthetized by an intraperitoneal injection of sodium pentobarbital $(50 \mathrm{mg} / \mathrm{kg} \mathrm{bw})$, subsequently each rat was fixed to a heating pad to prevent rapid cooling. Afterward, the whole thoracic cavity was fully exposed to perform heart perfusion with the $\left[\mathrm{I}^{125}\right]$ radio labeled IGF-1. This method was used in order to determine the binding kinetics between IGF-1 and its receptor subtype IGF-1R at the level of the coronary endothelium (CE, perfused rat heart without CHAPS) and the CM (CHAPS-perfused rat hearts).

\section{Tissue Preparation for Histological Studies}

The hearts were flushed with NSS until they were cleared out of blood. The washed hearts were injected in situ with about $1 \mathrm{~mL}$ of cold isopentane through the apex while still beating, and, then removed and snap frozen in the same solution (isopentane/dry ice). Each intact heart was then cut, starting at the apex, into four blocks by three planes parallel 
to the base. The tissues were then embedded in Jung Tissue Freezing Medium (Leica Instruments, Nusslock, Germany), cut with a cryostat into sections $4 \mu \mathrm{m}$ thick, and placed on gelatin-precoated glass slides (two sections per slide).

\section{Western Blotting}

The procedures as reported by Al-Jaroudi et al. (2005) and Karam et al. (2005) were followed. Samples of proteins from homogenate extracts of whole heart $(n=8)$ were quantified using the Bio-Rad DC Protein Assay (Bio-Rad Laboratory, CA, USA). The protein samples $(100 \mu \mathrm{g})$ were loaded and separated on $10 \%$ polyacrylamide gel by electrophoresis (Minigel electrophoresis unit, Protean III, Bio-Rad Laboratory, CA, USA). Protein bands were then transferred for 2 hours on nitrocellulose membranes (Transblot unit, Protean III, Bio-Rad Laboratory, CA, USA). Each membrane was blocked with a blocking buffer [prepared by mixing $25 \mathrm{~g}$ of dry non-fat milk with $25 \mu \mathrm{l}$ of Tween-20 and adding Tris Buffer Saline (TBS 1X, pH 7.4) up to $50 \mathrm{ml}$ ] for 1 hour then incubated overnight in cold room with the primary polyclonal antibody; polyclonal IGF-1R $\beta$ antibodies raised in rabbit (Santa Cruz Biotech, CA, USA) (diluted 1/500). The membrane was washed three times with TBS/Tween solution to remove the primary antibody. This was followed by incubating the membrane for 2 hours with the secondary antibody, anti-rabbit IgG-HRP $2^{\circ}$ (Santa Cruz Biotech., CA, USA) (diluted 1/2500). Afterward, the membrane was washed four times with TBS/Tween solution. Immunoblotted bands were detected by ECL (Enhanced Chemiluminescence), and developed on a Fuji Medical Xray film (Fuji Photo Film Co, LTD, Tokyo, Japan) by autoradiography (Fisher Scientific, Pittsburg, USA). Band thickness were determined by a semi-quantitative densitometric analysis (arbitrary unit) using a specific computer program (LabWorks45 Gel-Pro Application) and expressed as mean thickness \pm standard error mean (SEM).

\section{Indirect Immunofluorescence}

The IGF-1R receptor was assessed in the heart using indirect immunofluorescence $(n=8)$. First, the sections were blocked with rabbit serum for one hour; then, they were incubated with primary antibodies; anti-IGF-1R $\beta$ raised in rabbits (Santa Cruz Biotech., CA, USA) (diluted 1/5000) for 1 hour. The sections were then incubated with fluoresceinlabeled secondary antibody (Bovine Anti-Rabbit IgG FITC conjugate, Santa Cruz Biotech., CA, USA) (diluted 1/1000) for an additional 1 hour. Between incubations, the slides were washed in Phosphate Buffer Saline, PBS (0.01M) [0.1M PBS was made by mixing $19 \mathrm{ml}$ of solution A (3.45 g of $\mathrm{NaH}_{2} \mathrm{PO}_{4} \cdot \mathrm{H}_{2} \mathrm{O}$ in $250 \mathrm{ml} \mathrm{DW}$ ) with $81 \mathrm{ml}$ of solution $\mathrm{B}$ (17.9 g of $\mathrm{Na}_{2} \mathrm{HPO}_{4} .12 \mathrm{H}_{2} \mathrm{O}$ in $500 \mathrm{ml} \mathrm{DW}$ ] for 30 minutes. Finally, the sections were mounted with aqueous glycerin, and slides were then viewed using a UV light microscope. Negative controls included two types of sections where either the primary or the secondary antibodies were omitted.

\section{Data Analysis and Statistical Evaluation}

All data were expressed as mean values obtained for all the parameters mentioned above, per animal and per group. To evaluate significance among different experimental groups, the student's $t$-test and the analysis of variance for multiple factors (ANOVA) using the Bonferroni penalty method were used. Values were expressed as arithmetic means \pm SEM. The degree of significance was judged by $p$ values when necessary, where a $p$ value $<0.05$ indicated significance.

\section{RESULTS}

\section{Heart Perfusion Results}

Using a mathematical physical model [20], timedependent radioactive IGF-1 ([ $\left.\left.{ }^{125} \mathrm{I}\right]-\mathrm{IGF}-1\right)$ concentration curves were exploited to determine the IGF-1 forward binding constant $\left(\mathrm{k}_{\mathrm{n}}\right)$, reversal constant $\left(\mathrm{k}_{-\mathrm{n}}\right)$, dissociation constant $\left(\mathrm{k}_{\mathrm{d}}=\mathrm{k}_{\mathrm{n}} / \mathrm{k}_{\mathrm{n}}\right)$, and affinity (residency-time) constant $(\tau$ $=1 / \mathrm{k}_{\text {-n }}$ ) with its receptor subtype IGF-1R. These derived binding and affinity constants of IGF-1 to its receptor subtype on coronary endothelial cells (CE) and CM are shown in Tables $\mathbf{2}$ and $\mathbf{3}$ respectively. At the level of the CE (Table 2), there was a $28 \%$ increase in the $\tau$ value in the NL group compared to $\mathrm{N}(0.190 \pm 0.002$ vs $0.149 \pm 0.001 \mathrm{~min})$. Diabetes caused a $31 \%$ increase in the $\tau$ value compared to the $\mathrm{N}$ $(0.195 \pm 0.001 \mathrm{~min} v s 0.149 \pm 0.001 \mathrm{~min})$. Moreover, insulin treatment could not restore the $\tau$ value in the DI group to the normal value $(0.202 \pm 0.001 \mathrm{~min} v s 0.149 \pm 0.001 \mathrm{~min})$. The administration of losartan caused a $57 \%$ increase in the $\tau$ value compared to the $\mathrm{N}$ group $(0.234 \pm 0.001 \mathrm{~min} v s 0.149$ $\pm 0.001 \mathrm{~min}$ ) and a $20 \%$ increase in the $\tau$ value compared to the $\mathrm{D}$ group $(0.234 \pm 0.001 \mathrm{~min} v s 0.195 \pm 0.001 \mathrm{~min})$. However, insulin and losartan co-treatment in the DIL group was able to reduce the $\tau$ value elevation in diabetes $(0.179 \pm$ $0.001 \mathrm{~min} v s 0.195 \pm 0.001 \mathrm{~min}$ ) but not to the normal level $(0.179 \pm 0.001 \mathrm{~min} v s 0.149 \pm 0.001 \mathrm{~min})$.

Table 2. The Calculated Kinetic Parameters of IGF-1 with its Receptor Subtype at the Coronary Endothelium in Normal and Diabetic Rats

\begin{tabular}{|l|c|c|}
\hline \multicolumn{1}{|c|}{ Groups } & $\mathbf{K}_{\mathbf{d}}$ (Moles)*10 $^{-15}$ & $\boldsymbol{\tau}$ (Min) \\
\hline \hline Normal (N) & $0.291 \pm 0.001^{\mathrm{a}}$ & $0.149 \pm 0.001^{1}$ \\
\hline Normal + Losartan (NL) & $0.166 \pm 0.002^{\mathrm{b}}$ & $0.190 \pm 0.002^{2}$ \\
\hline Diabetic (D) & $0.215 \pm 0.001^{\mathrm{c}}$ & $0.195 \pm 0.001^{3}$ \\
\hline Diabetic + Insulin (DI) & $0.143 \pm 0.001^{\mathrm{d}}$ & $0.202 \pm 0.001^{4}$ \\
\hline Diabetic + Losartan (DL) & $0.220 \pm 0.001^{\mathrm{e}}$ & $0.234 \pm 0.001^{5}$ \\
\hline $\begin{array}{l}\text { Diabetic + Insulin + Losartan } \\
\text { (DIL) }\end{array}$ & $0.266 \pm 0.001^{\mathrm{f}}$ & $0.179 \pm 0.001^{6}$ \\
\hline
\end{tabular}

$(a, b),(a, c),(a, d),(a, e),(a, f),(b, c),(b, d),(b, e),(b, f),(c, d),(c, f),(d, e),(d, f),(e$, f) are significant.

$(1,2),(1,3),(1,4),(1,5),(1,6),(2,3),(2,4),(2,5),(2,6),(3,4),(3,5),(3,6)(4,5)$, $(4,6),(5,6)$ are significant.

At the CM level (CHAPS-perfused heart) (Table 3), there was a 7\% decrease in the $\tau$ value in the NL group compared to $\mathrm{N}(0.184 \pm 0.002$ vs $0.198 \pm 0.002 \mathrm{~min})$. Diabetes (D) caused a $28 \%$ increase in the $\tau$ value compared to the $\mathrm{N}$ $(0.253 \pm 0.001 \mathrm{~min}$ vs $0.198 \pm 0.002 \mathrm{~min})$. Moreover, insulin treatment in the DI group, although decreased the $\tau$ value $8 \%$ from its diabetic value $(0.234 \pm 0.001 \mathrm{~min} v s 0.253 \pm 0.001$ $\mathrm{min})$, could not restore it to the normal value $(0.234 \pm 0.001$ min $v s 0.198 \pm 0.002 \mathrm{~min})$. Furthermore, the administration of losartan in the DL group was not able to affect the $\tau$ value if compared to the $\mathrm{D}$ group $(0.251 \pm 0.001 \mathrm{~min} v s 0.253 \pm$ $0.001 \mathrm{~min}$ ). However, insulin and losartan co-treatment in 
the DIL group was able to nearly normalize the $\tau$ value elevation in diabetes back to its normal level $(0.203 \pm 0.001$ $\min v s 0.198 \pm 0.002 \mathrm{~min}$ ).

Table 3. The Calculated Kinetic Parameters of IGF-1 with its Receptor at the Cardiac Myocytes in Normal and Diabetic Rats (CHAPS- Perfused)

\begin{tabular}{|l|c|c|}
\hline \multicolumn{1}{|c|}{ Groups } & $\mathbf{K}_{\mathrm{d}}$ (Moles)*10 $^{-\mathbf{1 5}}$ & $\boldsymbol{\tau}$ (Min) \\
\hline \hline Normal (N) & $0.118 \pm 0.002^{\mathrm{a}}$ & $0.198 \pm 0.002^{1}$ \\
\hline Normal + Losartan (NL) & $0.164 \pm 0.002^{\mathrm{b}}$ & $0.184 \pm 0.002^{2}$ \\
\hline Diabetic (D) & $0.151 \pm 0.001^{\mathrm{c}}$ & $0.253 \pm 0.001^{3}$ \\
\hline Diabetic + Insulin (DI) & $0.109 \pm 0.001^{\mathrm{d}}$ & $0.234 \pm 0.001^{4}$ \\
\hline Diabetic + Losartan (DL) & $0.175 \pm 0.001^{\mathrm{e}}$ & $0.251 \pm 0.001^{5}$ \\
\hline $\begin{array}{l}\text { Diabetic + Insulin + Losartan } \\
\text { (DIL) }\end{array}$ & $0.205 \pm 0.001^{\mathrm{f}}$ & $0.203 \pm 0.001^{6}$ \\
\hline
\end{tabular}

(a, b), (a, c), (a, d), (a, e), (a, f), (b, c), (b, d), (b, e), (b, f), (c, d), (c, f), (d, e), (d, f), (e, f) are significant.

$(1,2),(1,3),(1,4),(1,5),(1,6),(2,3),(2,4),(2,5),(2,6),(3,4),(3,5),(3,6)(4,5)$, $(4,6),(5,6)$ are significant.

\section{Western Blot Analysis}

Band density was resolved by a semi-quantitative densitometric analysis (arbitrary unit) using a specific computer program. Results for the different groups (each group with sample size $n=8$ ) were expressed as the bands density aver- age \pm SEM (Fig. 1). Compared to the N, one can notice the insignificant increase in IGF-1R density in the NL and the DI. Moreover this receptor subtype expression was nearly normalized in the DL. Furthermore, there was a statistically insignificant decrease in the IGF-1R density in the D compared to the N. Finally, there was also a statistically insignificant decrease in the IGF-1R density in the DIL compared to the $\mathrm{N}$. The demonstration of equal loading of the protein extracts in the polyacrylamide gel wells was done by incubating the nitrocellulose membranes with IGF-1R antibodies and then staining with ponceau red (Fig. 1C).

\section{Immunohistochemistry}

Immunofluorescence was measured using a semiquantitative visual program based on the MATLAB software. Results show insignificant decreases in the IGF-1R density in the NL, and D groups as compared to N (Figs. $\mathbf{2 , 3}$. However, a significant decrease in fluorescence suggesting a decrease in IGF-1R density was noted in all of the three treated diabetic groups (DI, DL, \& DIL) compared to either $\mathrm{N}$ or $\mathrm{D}$ groups. Moreover, the decrease of fluorescence $(21.63 \pm 0.35$, Fig. 3) in the DIL group was significant when compared to the DI $(26.75 \pm 0.97$, Fig. 3) and DL (30.38 \pm 0.66 , Fig. 3) groups.

\section{DISCUSSION}

Cardiovascular disease secondary to diabetes mellitus is considered to be the chief cause of premature death [6,7]. If untreated, the cardiomyopathy that develops in diabetic pa-
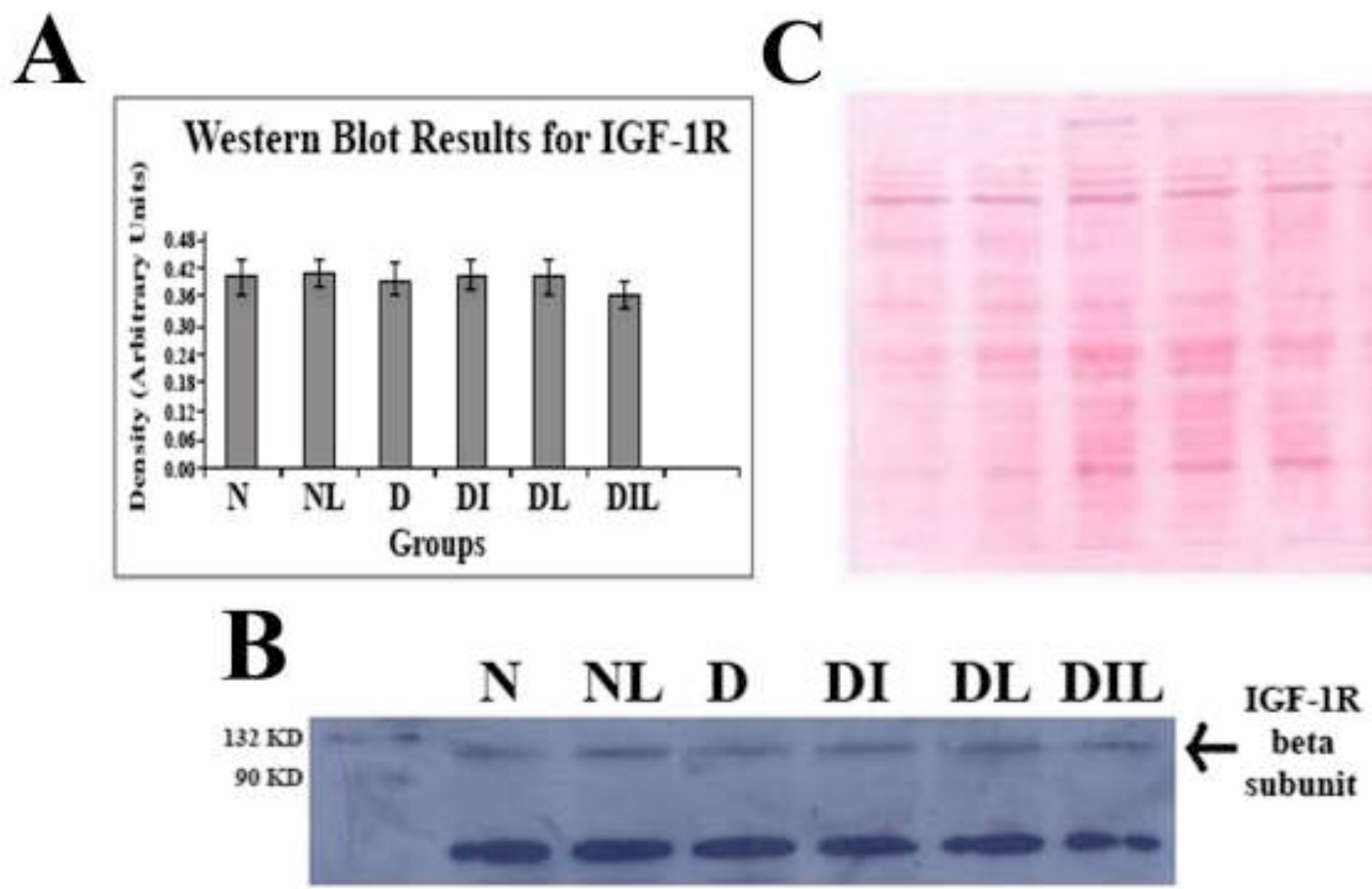

Fig. (1). A. Diagram representing the data obtained from the quantization of the bands of western blots done on heart protein extracts from the six different groups $(\mathrm{n}=8)$. Notice the statistically insignificant difference between the six different groups ( $\mathrm{p}>0.05)$. B. A representative western blot showing the expression of IGF-1R in cardiac homogenates. $100 \mu \mathrm{g}$ protein samples from cardiomyocyte extracts were immunoblotted with IGF-1R (beta subunit) antibody. C. A nitrocellulose membrane treated with anti IGF-1R $\beta$ and stained with ponceau red in order to check for equal loading. 
tients eventually leads to heart failure [7]. Growing attention is given to the insulin-like growth factors which are known to share many of insulin signaling cascades [1-3]. In the heart, various studies have suggested a certain role for insulin-like growth factor (IGF-1) in the complex regulation of myocardial structure and function. In addition, IGF-1 was found to play a role in the delay of apoptosis and in the prolongation of survival of CM [3-5]. Hence, IGF-1 is a true candidate for cardioprotective therapy in diabetes mellitus. This study aimed at tackling the effects of insulin and $\mathrm{AR}_{1} \mathrm{~B}$ combination therapy on the modulation and affinity of the IGF-1 receptor subtype in STZ-diabetic rat hearts.
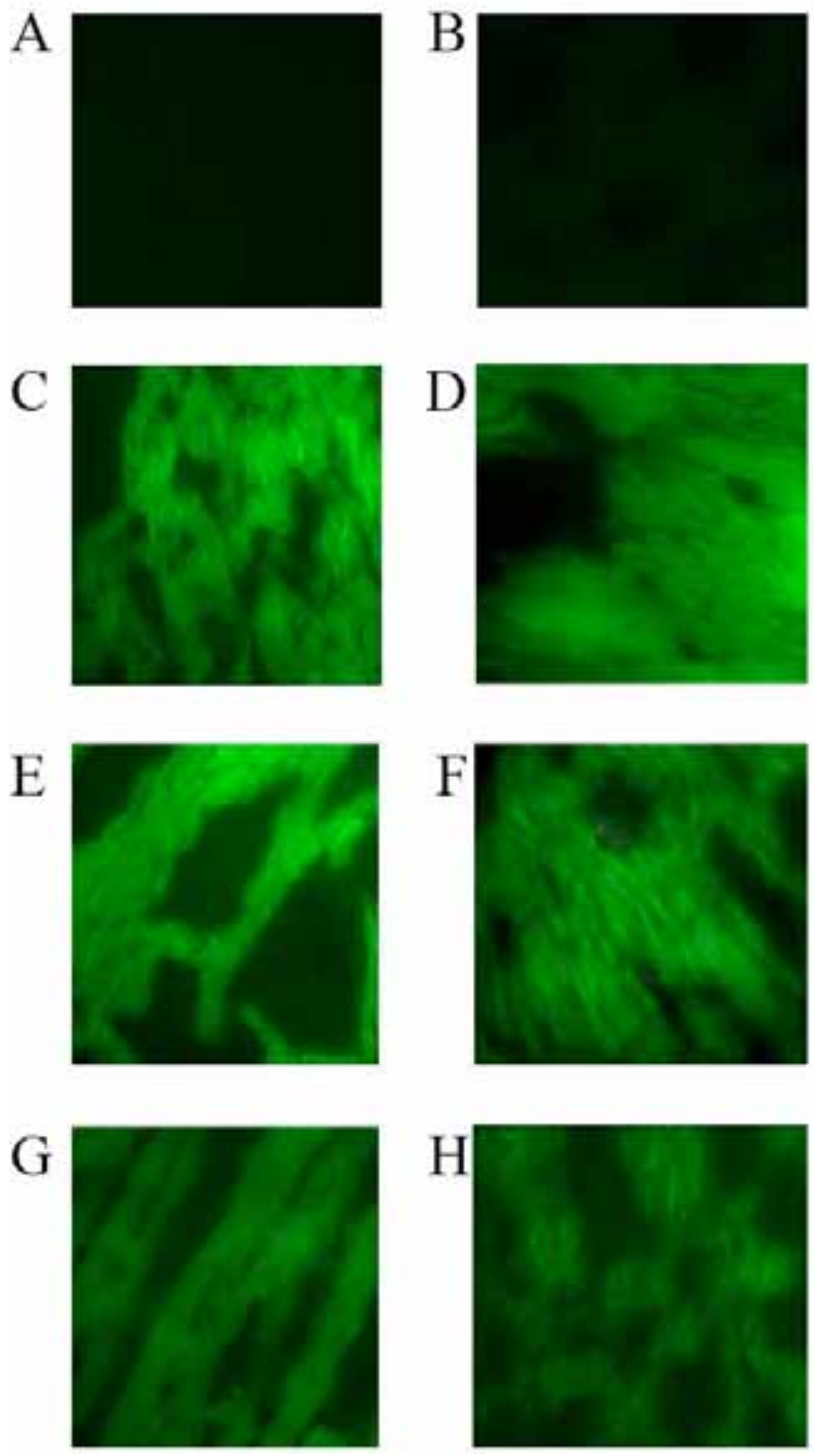

Fig. (2). Immunofluorescence showing the localization of IGF-1R on cardiomyocytes of the different groups of rats. $\mathbf{A}$ and $\mathbf{B}$ are sections from normal animals representing the negative controls without the primary and secondary antibodies respectively; no signal is noted. No change in the density of these receptors is noticed between N (C), NL (D), D (E), and DL $(\mathbf{G})$ groups. DI $(\mathbf{F})$ and DIL (H) groups exhibit a decrease in IGF-1R density when compared to the other groups.

Heart perfusion was used to determine the binding affinity (using the $\tau$ value) of IGF- 1 to its receptor subtype both at the level of the CE (CHAPS-untreated rats) and the CM
(CHAPS-treated rats). Using a physical-mathematical model $[20,21]$, heart perfusion results show that IGF-1 affinity to its receptor subtype increased in all diabetic groups at the $\mathrm{CE}$ level (Table 2) and that the co-treatment with insulin and losartan in the DIL group managed to decrease this affinity but not to the normal level seen in N. Taking these data into consideration, we could say that the interaction between insulin and $\mathrm{AT}_{1}-\mathrm{R}$ blockade is needed to modify the IGF-1R binding affinity at the $\mathrm{CE}$ level. Therefore, the cross-talk between insulin and the $\mathrm{AT}_{1}-\mathrm{R}$ seems to have an influence to IGF-1 binding kinetics on coronary endothelial cells.

At the level of cardiac myocytes (CHAPS-treated), we again noted an increase in the IGF-1R affinity in the D and DL groups (Table 3). The decreased affinity in the DI group, compared to the D and DL groups, is trivial with respect to the normal, maybe because insulin treatment was insufficient. On the contrary, one can notice the normalization of IGF-1R affinity when diabetic rats were co-treated with insulin and losartan (DIL), re-emphasizing the role of the crosstalk between insulin and Ang II on the binding kinetics of IGF-1. With respect to the NL group, there was an increase in IGF-1R binding affinity at the CE level and a decrease at the CM level compared to the normal, probably hinting to spatial differences between the different signaling cascades. Summed together, the increased IGF-1 affinity to its receptor at both the coronary endothelial and cardiomyocyte levels can be considered as one of the late alterations imposed by diabetes on the heart tissue. This alteration could be aiding in the wide hypertrophic changes seen in late stage diabetic heart [8]. On the contrary, insulin and losartan treatment was able to reduce this affinity, and thus may delay, or even prevent this type of myocardial remodeling as observed in our previous studies [8].

Western blot, done on protein extracts from rat heart homogenates to assess the variation in the IGF-1 receptor subtype density among the different treatment groups, showed a slight decrease in IGF-1 density in D, compared to the $\mathrm{N}$, but not significantly comparable to the reduction in IGF-1R density reported in previous studies [3,5] (Fig. 1). In addition, one can see that insulin or losartan supplementation in diabetes (DI \& DL) had no normalizing effects with respect to this receptor density (Fig. 1). On the other hand, the decreased IGF-1R density in DIL could hint to a cross-talk between insulin and Ang II regarding IGF-1R expression in the heart. Finally, our western blot results show that there is not a strong effect of late stage diabetes on IGF-1R expression.

Immunofluorescence proved that IGF-1Rs are localized at the level of cardiac myocytes (Fig. 2). Quantification of immunofluorescence using a specific computer program showed that, there was a comparable IGF-1R density in the N, NL, D, and DL groups (Fig. 3). However; insulin treatment in both the DI and DIL group was able to decrease this density compared to the other study groups (Fig. 3). In addition, both the western blot and the immunofluorescence results of the DIL group indicated definite reduction of IGF$1 \mathrm{R}$ expression and localization at the heart level. Therefore these results can postulate that IGF-1R expression, and the binding episode with its substrate may be playing a key role in cardiac protection and prevention of damage in this treatment modality [8]. In conclusion, these findings reinforce the 


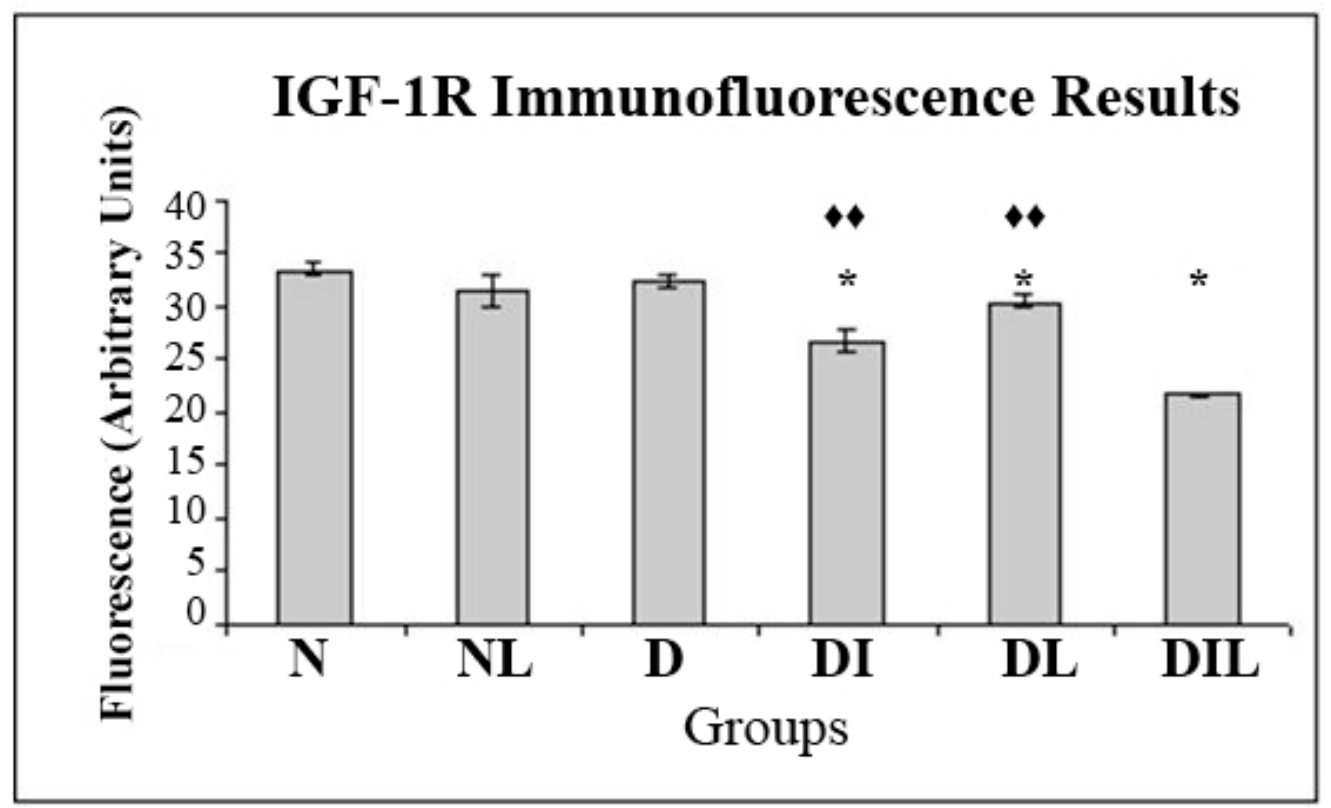

Fig. (3). Diagram representing the immunofluorescence semi-quantitated results $(\mathrm{n}=8)$. The symbol $\mathrm{s} *$ and $\bullet$ indicate significance $(\mathrm{p}<0.05)$ as compared to $\mathrm{N}$ and DIL respectively.

likely presence of a complex cross-talk among the IGF-1, Ang II, ET-1, and insulin systems.

\section{ACKNOWLEDGEMENTS}

Authors would like to acknowledge funding from the University Research Board and Medical Practice Plan of the American University of Beirut, and the generous help of $\mathrm{Mr}$. Firas Zeinnedine in the preparation of the fluorescence reading program.

\section{REFERENCES}

[1] Párrizas M, Saltiel AR, LeRoith D. Insulin-like growth factor 1 inhibits apoptosis using the phosphatidylinositol 3'-kinase and mitogen-activated protein kinase pathways. J Biol Chem 1997; 272 : 154-61.

[2] Kurmasheva RT, Houghton PJ. IGF-I mediated survival pathways in normal and malignant cells. Biochim Biophys Acta 2006; 1766: 1-22.

[3] Saetrum Opgaard OS, Wang PH. IGF-I is a matter of heart. Growth Horm IGF Res 2005; 15: 89-94.

[4] Lee WL, Chen JW, Ting CT, Ishiwata T, Lin SJ, Korc M, Wang PH. Insulin-like growth factor I improves cardiovascular function and suppresses apoptosis of cardiomyocytes in dilated cardiomyopathy. Endocrinology 1999; 140: 4831-40.

[5] Chen HS, Shan YX, Yang TL, Lin HD, Chen JW, Lin SJ, Wang PH. Insulin deficiency downregulated heat shock protein 60 and IGF-1 receptor signaling in diabetic myocardium. Diabetes 2005; 54: 17581.

[6] Connelly K, Kelly DJ, Langham R, Krum H, Gilbert RE. Drug therapy for the cardiac complications of diabetes. Drug Discov Today Ther Strateg 2004; 1: 195-200.

[7] Sander GE, Wilklow FE, Giles TD. Heart failure in diabetes mellitus: causal and treatment considerations. Minerva Cardioangiol 2004; 52: 491-503.

[8] Al Jaroudi WA, Nuwayri-Salti N, Usta JA, et al. Effect of insulin and angiotensin II receptor subtype-1 antagonist on myocardial remodelling in rats with insulin-dependent diabetes mellitus. J Hypertens 2005; 23: 381-92.

[9] Wang P, Almahfouz A, Giorgino F, McCowen K, Smith R. In vivo insulin signaling in the myocardium of streptozotocin-diabetic rats: opposite effects of diabetes on insulin stimulation of glycogen synthase and c-Fos. Endocrinology 1999; 140: 1141-50.

[10] Elbaz N, Bedecs K, Masson M, Sutren M, Strosberg AD, Nahmias C Functional trans-activation of insulin receptor kinase by growth inhibitory angiotensin II AT2 receptor. Mol Endocrinol 2000; 14: 795804.

[11] Velloso LA, Folli F, Perego L, Saad MJ. The multi-faceted cross-talk between the insulin and angiotensin II signaling systems. Diabetes Metab Res Rev 2006; 22: 98-107.

[12] Clauser E. Synthesis and local and distant actions of vasoactive peptides. Ann Endocrinol (Paris) 2000; 61: 10-5.

[13] Velloso LA, Folli F, Sun XJ, White MF, Saad MJ, Kahn CR. Crosstalk between the insulin and angiotensin signaling systems. Proc Natl Acad Sci USA 1996; 93: 12490-5.

[14] Kim S, Iwao H. Molecular and cellular mechanisms of angiotensin IImediated cardiovascular and renal diseases. Pharmacol Rev 2000; 52 11-34.

[15] Schwartz F, Duka A, Duka I, Cui J, Gavras H. Novel targets of ANG II regulation in mouse heart identified by serial analysis of gene expression. Am J Physiol Heart Circ Physiol 2004; 287: H1957-66.

[16] Nouet S, Amzallag N, Li JM, et al. Trans-inactivation of receptor tyrosine kinases by novel angiotensin II AT2 receptor-interacting protein, ATIP. J Biol Chem 2004; 279: 28989-97.

[17] Fiordaliso F, Li B, Latini R, et al. Myocyte death in streptozotocininduced diabetes in rats is angiotensin II-dependent. Lab Invest 2000 80: 513-27.

[18] Berk BC. Angiotensin II signals transduction in vascular smooth muscle: pathways activated by specific tyrosine kinases. J Am Soc Nephrol 1999; 10: S62-8.

[19] Karam CN, Nuwayri-Salti N, Usta JA, et al. Effect of systemic insulin and angiotensin II receptor subtype-1 antagonist on endothelin-1 receptor subtype(s) regulation and binding in diabetic rat heart. Endothelium 2005; 12: 225-31.

[20] Haddad RE, Jurjus AR, Ibrahim MZ, et al. Binding of 125I-insulin on capillary endothelial and myofiber cell membranes in normal and streptozotocin-induced diabetic perfused rat hearts. Comp Biochem Physiol A Physiol 1997; 117: 523-30.

[21] Bikhazi AB, Khalifeh AM, Jaroudi WA, Saadeddine RE, Jurjus AR, El-Sabban ME. Endothelin-1 receptor subtypes expression and binding in a perfused rat model of myocardial infarction. Comp Biochem Physiol C Toxicol Pharmacol 2003; 134: 35-43. 